\title{
Effective Continuing Professional Learning and Development: The Case of Mathematics Teachers in Malta
}

\author{
Robert Vella ${ }^{1 *}$ and Jo-Ann Azzopardi ${ }^{2}$ \\ ${ }^{1}$ MCAST, The Malta College of Arts, Science and Technology, Malta \\ ${ }^{2}$ Department of Education, Malta
}

*Corresponding author: Robert Vella, MCAST, The Malta College of Arts, Science and Technology, Malta

ARTICLE INFO

Received: 幽 December 02, 2021

Published: January 04, 2022

Citation: Robert Vella, Jo-Ann Azzopardi. Effective Continuing Professional Learning and Development: The Case of Mathematics Teachers in Malta. Biomed J Sci \& Tech Res 40(5)-2022. BJSTR. MS.ID.006502.

Keywords: Professional Development; Mathematics; Secondary Teachers; Opportunities

\begin{abstract}
Teachers play a key role in every student's academic journey, and their attitude towards teaching and their level of preparation has direct impact on students' achievement. Teaching within a dynamic and ever-changing educational sphere, influenced by constant educational reforms, is complex. Professional development (PD), hence, plays a crucial role in supporting teachers, their learning and professional growth. This studyaimed to understand the PD opportunities for secondary mathematics teachers in Malta and to explore how these help teachers to develop their professional learning and address their needs. Using a phenomenological research design and a mixed methods approach, data was gathered via a questionnaire followed by three focus groups. Findings show that teachers view PD as vital for their development, but the PDs should be based on the teachers' needs. Teachers seek out PDs mainly to support their teaching, and to increase student motivation and enthusiasm towards mathematics.
\end{abstract}

Abbreviations: PD: Professional Development; MEDE: Ministry for Education and Employment; NMC: National Minimum Curriculum; NCF: National Curriculum Framework; DQSE: Directorate for Quality and Standards in Education; PLCs: Professional Learning Communities; FREC: Faculty of Education Research Ethics Committee; UREC: University of Malta Research Ethics Committee; HOSs: Head of Schools; ITE: Initial Teacher Education; SLT: School Leadership Team

\section{Introduction}

Education in Malta falls under the responsibility of the Ministry for Education and Employment (MEDE) and is compulsory between the ages of 5 to 16 years. At present, students aged between 11 to 16 years can attend one of the 22 church secondary schools, 11 independent secondary schools and 23 state middle and secondary schools. The last two decades have been characterised by several successive reforms in the Maltese education system. The National Minimum Curriculum (NMC), based on fifteen curricular principles was introduced in 1999. Next followed the National Curriculum
Framework (NCF) introduced in 2012, as a result of a review of the NMC, which aimed to take into consideration new realities in the education system such as the use of new technologies and the drive towards inclusion, differentiated and mixed-ability teaching.

The latest education framework, the Framework for the Education Strategy for Malta 2014-2024, proposes a more "equitable quality education and promoting lifelong learning opportunities for all" MEDE [1]. The teaching of mathematics in Malta is compulsory in all school cycles. Guidelines proposed by the 
Directorate for Quality and Standards in Education (DQSE) for the teaching, learning and assessment of mathematics in Malta state that due to the nature of mathematics, "there is no single best way to teach mathematics" and proposes "that educators use a variety of teaching approaches in order to cater for [all] aspects", such as "teaching through exposition", "teaching through discovery" and/ or "teaching through exploration" DQSE [2]. In Maltese middle and secondary schools, on average, mathematics is allocated 5 fortyminute lessons per week, usually one lesson per day.

\section{Defining Professional Development}

Literature provides various definitions of professional development (PD) for teachers. In a broad sense, PD can be defined as the development of a teacher's professional role, and occurs as "a combination of personal and professional events that teachers experience during their time at work and [which act] as a key to reforms in teaching and learning" Maskit [3]. PD activities can include formal experiences, such as attending workshops and in-service courses, or less formal experiences such as reading professional literature and discussions with colleagues. Hunzicker [4] states that PD is "anything that engages teachers in learning activities that are supportive, job-embedded, instructionally focused, collaborative, and ongoing". Such form of professional learning is likely to help inspire teachers and keep them engaged. More importantly, PD helps them innovate the way they teach as they learn about different methods and best practices utilised by colleagues, and helps support teachers to be better prepared for changes in policy and in curriculum Fullan [5]. PD activities should "seek to update, develop and broaden the knowledge teachers acquired during initial teacher education and/or [to] provide them with new skills and professional understanding" OECD [6] throughout their career.

\section{Professional Development of and for Mathematics Teachers}

Many mathematics teachers teach through practices based heavily on fact memorisation without trying to generate a deeper understanding of the subject and without utilising problem-solving techniques Darling-Hammond, et al. [7]. Teachers' prior knowledge and learning experiences affect the way they teach Beswick [8] and, according to Cohen [9], only when pre-conceptions of knowledge as facts, teaching as telling and learning as memorising are dispelled, can teachers teach for understanding. The main focus of teacher learning activities, especially for mathematics teachers, should be on mathematical content and pedagogy and analysis of teachers' work with students that include learning about "specific teaching practices [to] increase teachers' use of those practices in the classroom" Desimone [10]. Argue that PD focused on specific mathematical content and on the ways how students learn is especially beneficial particularly for instruction designed to improve students' understanding of concepts.

Buhagiar [11] provides a number of insights with regards to PD for mathematics teachers. He states that PD should serve to create spaces where teachers' prior knowledge and experiences interact with reform initiatives and learning opportunities. In addition, Buhagiar [11] argues that it helps that the school culture is conducive to change, and teachers benefit most from PD when they form part of a professional learning community. Garet [12] suggest a number of structures that can characterise a mathematics PD program so that it may bring about teacher learning. Sustained and intensive PD activities, ideally spread over a span of time, aligned to national standards and assessment procedures, and focused on improving the teachers' mathematical content and teaching pedagogy, are mentioned as important features.

PD is not a "one-size-fits-all" issue Loucks-Horsley [13] and a program that is successful for one school may fail when replicated in another school. Putnam [14] list various approaches that can be utilised as learning experiences for mathematics teachers in schools. In-class observation of mathematical activities and subsequent sharing of insights about students' mathematical understanding with teachers can be one such approach, where teachers learn from actual teaching experiences, thus making learning more pragmatic. Another approach is to have teachers share experiences and issues encountered while teaching along with students' work to serve as a basis for discussion. A third approach can be teachers learning about theoretical and research-based ideas during which teachers create learning activities for their students which are then actually tried out and tested in class. These sessions provide opportunities for teachers to "develop different conceptions of mathematics and deeper understandings of mathematical learning and teaching, and to incorporate strategies such as group problem solving, use of manipulatives, and non-routine problems into their mathematics instruction" Putnam [14]. [14] suggest that a mix of approaches situated in diverse contexts might offer a promising approach to providing worthy teacher learning experiences.

\section{Teacher Perceived Effectiveness of Professional Devel- opment}

Effectiveness of PD is very difficult to define, particularly since what makes PD effective is likely to be perceived differently by teachers. Numerous studies have been conducted, with various researchers providing particular "characteristics of professional development that teachers ... value and [which teachers] believe help improve their practice" Quick [15]. A study conducted by Porter [16] based on the Eisenhower Program supporting highquality professional development in mathematics and science, specifies six main features of effective PD. These features are 
classified into two categories: core and structural Porter, et al. [16]. Core features include a focus on content, where the PD aim is about "what students are expected to learn (content knowledge) and how students learn the subject matter (pedagogical knowledge)" Quick, et al. [15] active learning where teachers need to "become actively engaged in the meaningful analysis of teaching and learning" Porter et al. [16] by being given feedback on their teaching Calleja [17] and coherence, where PD activities are connected to school or national goals and to other learning opportunities to create a comprehensive teaching program. Structural features include the form of the PD activity, that is whether the PD activity is focused on a small group or a large group; the duration of the activity and whether the sessions are spread over a span of time; and whether the level of teacher collaborative participation is across participants from the same school or across colleges and schools Porter, et al. [15-17].

In the case study conducted by Buhagiar [11], where the story of a Maltese mathematics teacher is presented, Buhagiar [11] states that to be effective, a professional learning program needs to instil a sense of change in the learner. Teachers' prior beliefs and experiences, "inherited through patterns of instruction" Cohen [9] and their "resistance to adventurous instruction" (p. 34) affect what teachers learn. Thus, "teacher education programmes ... are more likely to have an impact on teacher learning should they present learning as situated, with theory and practice constantly feeding into and developing each other" Buhagiar [11]. In his report about a small group of Maltese secondary school mathematics teachers participating in a PD program aiming to support teachers to teach mathematics through inquiry, Calleja [17] concludes that for a PD program to be effective, teachers need to participate in learning actively, be immersed in practice-based understandings and form part of a community of practice. Calleja [17] suggests that PD providers "no longer conceive teacher professional development as an isolated venture of off-site workshop training disconnected from practice, [but] rather ... an ongoing collaborative on-site experience of practice-oriented development and learning" Calleja [17].

\section{Professional Learning Communities}

Many mathematics teachers tend to work in isolation Krainer [18]. In recent years, with the introduction of various educational reforms, schools are being encouraged to provide opportunities for greater interaction amongst teachers. Thus, the introduction of the professional learning communities (PLCs) in or across schools, where teachers meet, discuss and learn from each other is encouraged Ministry of Education [19] [NMC]; MEDE, [20] [NCF]). Through PLCs, teachers are both inquirers and learners, sharing their mastery and know-how and learning with and from colleagues Fullan [21]. PLCs offer a useful approach for "informing and improving the professional practice of [an] entire team" DuFour [22], where teachers focus on learning rather than teaching, working together collaboratively while all the time holding themselves accountable for their students' results, thus aiming at finding the best teaching practices for their students to gain an optimal result DuFour [23]. McLaughlin [24] state that to be successful in constructing new methodologies, teachers need to participate in a PLC "that discusses new teacher materials and strategies, and that supports the risk taking and struggle entailed in transforming practice". The concept of schools as PLCs also requires individual schools to build strong networks and relations with other teachers and schools, to be able to share experiences and resources and to learn from others facing similar or different challenges OECD [6].

\section{Conclusion}

Teachers are agents in their own professional learning Ball [25] and use PD opportunities to satisfy a variety of wants and needs. The ultimate aim of PD is to better address teacher professional growth, to broaden teachers' thinking and to facilitate change Liljedahl [26]. Various definitions of PD were provided in an attempt to arrive to an understanding of how teachers perceive PD. Teachers' perceived effectiveness of PD was explored, and the importance of PLCs in schools and the kind of support teachers need were also investigated.

\section{Methodology}

This study attempts to understand and give meanings to the experiences of mathematics teachers' with regards to PD based upon their views and their specific work contexts so as to obtain a richer understanding of the phenomenon and to "generate or inductively develop a theory or pattern of meaning". Creswell [27]. Thus, an inductive constructivist grounded theory approach was adopted, where the exploration "examines the ways in which events, realities, meanings, experiences ... are the effects of a range of discourses operating within society" Braun [28] and theories are built according to the interpretations.

\section{Participants}

The study targeted mathematics teachers teaching in state and non-state schools, hailing from all secondary school sectors in Malta and Gozo. To obtain a representative sample of the population, a probability sample approach was employed in this research to "keep the sampling error to a minimum" Bryman [29]. A population of 360 teachers were invited to participate in the quantitative part of the study. 261 teachers working in 21 Church, 3 Independent and 22 State middle and secondary schools took part in the questionnaire, attaining an overall total participation rate of $72.5 \%$ of the mathematics teachers, with responses gathered from $76.2 \%$, $32.5 \%$ and $78.3 \%$ of the teachers respectively teaching in Church, Independent and State middle and/or secondary schools. These 
figures guarantee a maximum margin of error of 3.19\%, assuming a 95\% confidence interval. This helps determine the "interval or range in which ... [the] population score would likely fall" Creswell [30] and which is most likely to contain the population mean, thus helping to validate the conclusions formulated through the study. The sampling of the qualitative part of the study was composed of 13 teachers taking part in three different focus groups, with Focus Group 1, 2 and 3 having 6, 4 and 3 participants respectively.

\section{Approach}

A mixed method approach was utilised for this study. This method allowed the gathering of substantial amount of data, which then was merged, integrated, linked and embedded into themes Creswell [31]. Piloting is considered an important instrument to test the procedures and concepts in a study Schutt [32]. Hence, both the questionnaire and the focus group questions were piloted and valid suggestions were taken into consideration to obtain clearer questions. In this study, quantitative data was gathered by administering a questionnaire at the beginning of the study. Planned out questions helped address the following research questions: What type of CPD activities do mathematics teachers participate in?; What encourages and hinders teachers' participation in PD?; and Which PD opportunities do teachers perceive as most effective and why? The questionnaire helped to get an initial 'feel' of the data about teachers' perceptions with regards to PD and related issues, and to construct statistical models in an attempt to explain the experiences of mathematics teachers.

Table 1: Table showing information about the teacher questionnaire structure.

\begin{tabular}{|c|c|}
\hline \multicolumn{2}{|c|}{ Questionnaire } \\
\hline Section A & Section B \\
\hline $\begin{array}{l}\text { a. Teachers asked to provide } \\
\text { general information about } \\
\text { - Themselves } \\
\text { - their level of education } \\
\text { - their teaching experience } \\
\text { - the school sector in which they } \\
\text { teach } \\
\text { b. } 5 \text { close-ended questions }\end{array}$ & $\begin{array}{l}\text { a. Teachers asked to provide their } \\
\text { views with regards } \\
\text { - participation in CPD activities, } \\
\text { both compulsory and voluntary } \\
\text { - the impact of PD activities on } \\
\text { teacher development and learning } \\
\text { - factors which motivate teachers } \\
\text { to pursue a PD course } \\
\text { - teacher opinion about } \\
\text { effectiveness of PD sessions } \\
\text { attended } \\
\text { b. } 4 \text { open-ended questions and } 3 \\
\text { Likert scale questions - } 7 \text { questions } \\
\text { in total }\end{array}$ \\
\hline
\end{tabular}

Table 1 below provides information about the questionnaire. With regards to qualitative data, three focus group interviews were conducted. The questions used were based on results obtained from the analysis of data gathered through the questionnaire.
The qualitative data was analysed and cross-referenced with the quantitative data gathered and with the research literature. This helped provide a better understanding of Maltese mathematics teachers' professional learning experiences. The questions focused on: their career journey; how teachers view CPD; what PD should focus on to motivate teachers; the importance of teacher collaboration to engage in PD activities; what is an ideal and effective PD; impacts of having compulsory or voluntary CPD sessions; and any other comments the participants wanted to add.

\section{Analysis}

The quantitative data was analysed by using descriptive statistics and IBM SPSS Statistics 25 software. Two tests were used, the Chi-Square test and the Friedman test. The Chi-Square test is "a non-parametric tool designed to analyse group differences when the dependent variable is measured at a nominal level" McHugh [33]. Two questions were analysed using this test: the relation between the respondents' participation in particular PD activities and the impact of this PD experience on the teachers' development; and the relation between participation in voluntary PD activities and teachers' preference to participate in such activities. The Friedman test was used to compare mean rating scores provided to a number of related statements. The "method tests the hypothesis that the values of the variate corresponding to each subdivision by one of the factors is homogeneous, i.e., from the same universe" Friedman [34]. This test was used to analyse the extent to which the participants feel that the statements provided are a motivator towards their PD. Thematic analysis was used as a method for qualitative data analysis, defined by Braun [28] as "a method for identifying, analysing and reporting patterns [themes] within data." The data was analysed repeatedly and inductively generating in vivo codes until data saturation was reached. In order to facilitate better readability of the text, any quotes in Maltese were translated into English, and the English version was used.

\section{Ethical Implications}

Official approval from the Faculty of Education Research Ethics Committee (FREC), the University of Malta Research Ethics Committee (UREC), the Ministry of Education and Employment (MEDE), from the Secretariat for Catholic Education, and from the Head of Schools (HoSs) of all Church, Independent and State schools in Malta and Gozo, were sought and obtained. During every stage of the study, all necessary precautions were taken so that the study was not harmful to any participant involved, both during the research and afterwards. Hence, before conducting the questionnaires and the focus group interviews, the participants were reminded that participation was voluntary and that they could discontinue at any time. With regards to the focus group interviews, the participants were asked to sign a consent form. Participants 
were assured that they were free not to answer any of the prompts utilised for the interview and could terminate the interview at any time. Participants were also granted the possibility of going 'off the record' at any time. With the participants authorisation, the discussion was audio recorded. A transcription of the discussion was given to them for member checking Koelsch [35]. Concurring with Schutt [32], pseudonyms were utilised for storing and reporting all data throughout the study.

\section{Findings}

Five key themes emerged from the data analysis: teachers beliefs with regards PD; those learning activities, both compulsory and voluntary, that teachers report to have participated in; motivating reasons that encourage teachers to attend PD; number of barriers that hinder teachers from pursuing PD; and evaluation of the PD opportunities based on the teachers' expectations and proposed improvements.

\section{Teachers' Perceptions of Professional Development}

Mathematics teachers are very conscious that PD is a salient and integral feature in their job. This was particularly evident in the focus group discussions as teachers continually linked changes in pedagogical practices and learning of new skills to PD support. Teachers, almost unanimously agreed about the importance of attending PD, also stating that this is a must. Data from the questionnaire sheds light on how mathematics teachers view PD. PD is an ongoing process of acquiring knowledge and training throughout an educator's professional career. PD is a lifelong process of learning. It enhances your knowledge in the subject that you are teaching. It also helps you to reflect on your method of teaching and learn new skills for effective teaching. Although initial teacher education (ITE) is essential for a prospective teacher to develop necessary professional knowledge and gain a good theoretical and practical foundation on which to build one's profession, teachers stated that learning following ITE is equally important. Some teachers declared that certain issues are learnt through first-hand experience but also by learning with and from colleagues through the sharing of experiences. The following excerpts illustrate some teachers' positions: As you go along and encounter certain new experiences, you realise how much training you need in certain areas. Initial teacher training done at university, with mine occurring quite some time ago, still does not prepare you enough! You are unprepared for certain issues encountered in class.

\section{Engagement in Professional Development Activities}

Participants mentioned attending a variety of learning activities. For some, attendance is mandatory and mostly held during working hours, while other activities are voluntary and held within school hours, or self-sought and held after school hours. Teachers reported that they were either currently attending or have had the opportunity to attend at least one PD activity during the last two years. Participants frequently expressed the need to liaise and collaborate actively with colleagues from their own school or from other schools. Reasons stated were to "ensure a better end product" as inputs from various sources help in the fine tuning of lesson plans, activities, tests and/or resources, and also help reduce the workload. One can really learn from teaching peers by planning together and sharing ideas, resources and good teaching practices. Working in teams helps us achieve more. Subject meetings are important to plan, discuss and prepare lessons and handouts with other mathematics teachers.

Teachers also mentioned other learning opportunities occurring within a classroom setting, such as co-teaching and peer assessment. Co-teaching involves teachers working together with groups of students, sharing planning, teaching and assessing to provide differentiated instruction Friend [36]. During peer observation, teachers observe each other teaching to develop their own classroom practice. I have been co-teaching with another teacher for three years. I have recently started teaching a new subject, and I have learnt how to tackle certain issues by observing my colleague, and through practice. Observing peers and co-teaching are excellent learning experiences. Although apparently limited, such close collaborations seem to occur with teachers who embrace certain qualities such as being willing to share their knowledge and expertise, are trustworthy, are "at ease in each other's company" and respect each other. According to these teachers, while these collaboration practices should be encouraged, they cannot be imposed. Some teachers also mentioned that they sought their own PD opportunities. These activities are done in their own free time and in certain instances, without the constraints of a formal setting. A vast and diverse number of courses are available every year, and attending such a course, either physically or by distance learning, is a route that one can take.

Reading mathematics related articles also helps teachers gain valuable insights in new areas of mathematics education and may benefit from ideas and insights that can be incorporated in one's teaching Broemmel [37]. As a participant stated, Reading articles and professional literature can help you enhance your knowledge on the subject.

\section{Reasons Motivating Teachers to seek Professional Development}

Teachers frequently expressed their need to be prepared to face diverse situations encountered in their daily teaching, thus citing a variety of reasons motivating them to seek PD. Data from the questionnaire showed that teachers' primary reason for attending PD is to "improve my day-to-day teaching and classroom practice". Several participants stated that PD offers opportunities for 
"improving one's pedagogy" by "trying out new ways of teaching" and "reflecting on new concepts". Reasons explaining why enhancing one's teaching skills is important were "to be equipped to do the job better", "to keep up to standard", and "to be more effective in one's teaching", amongst others. A participant also stated that attending PD can be an opportunity to "rectify one's weakness".

Some participants felt that PD should provide them with an opportunity to develop professionally by "improving the mathematical content" or by "gaining new insights about the subject", although as one focus group participant stated, With regards to the teaching of mathematics, help is not really needed to learn more about the content but more about other issues, such as different methods of teaching. Other teachers stated that they chose to attend PD for their own personal self-growth, aiming at improving their present level of knowledge with aspirations to master new areas directly or indirectly related to their profession. Few participants stated that they sought PD targeting specific areas, to become "more successful and advance in their career" and to "get a better pay". Data from the questionnaire indicated that these motivators scored relatively low mean rating scores (Figure 1), thus implying that few participants deem these motivators as crucial for seeking PD. As a participant stated: With regards to eventually better my pay, we don't have many chances of increasing our pay; even if it does increase, it is not by much. More motivation can be achieved if teachers are paid like other professionals.

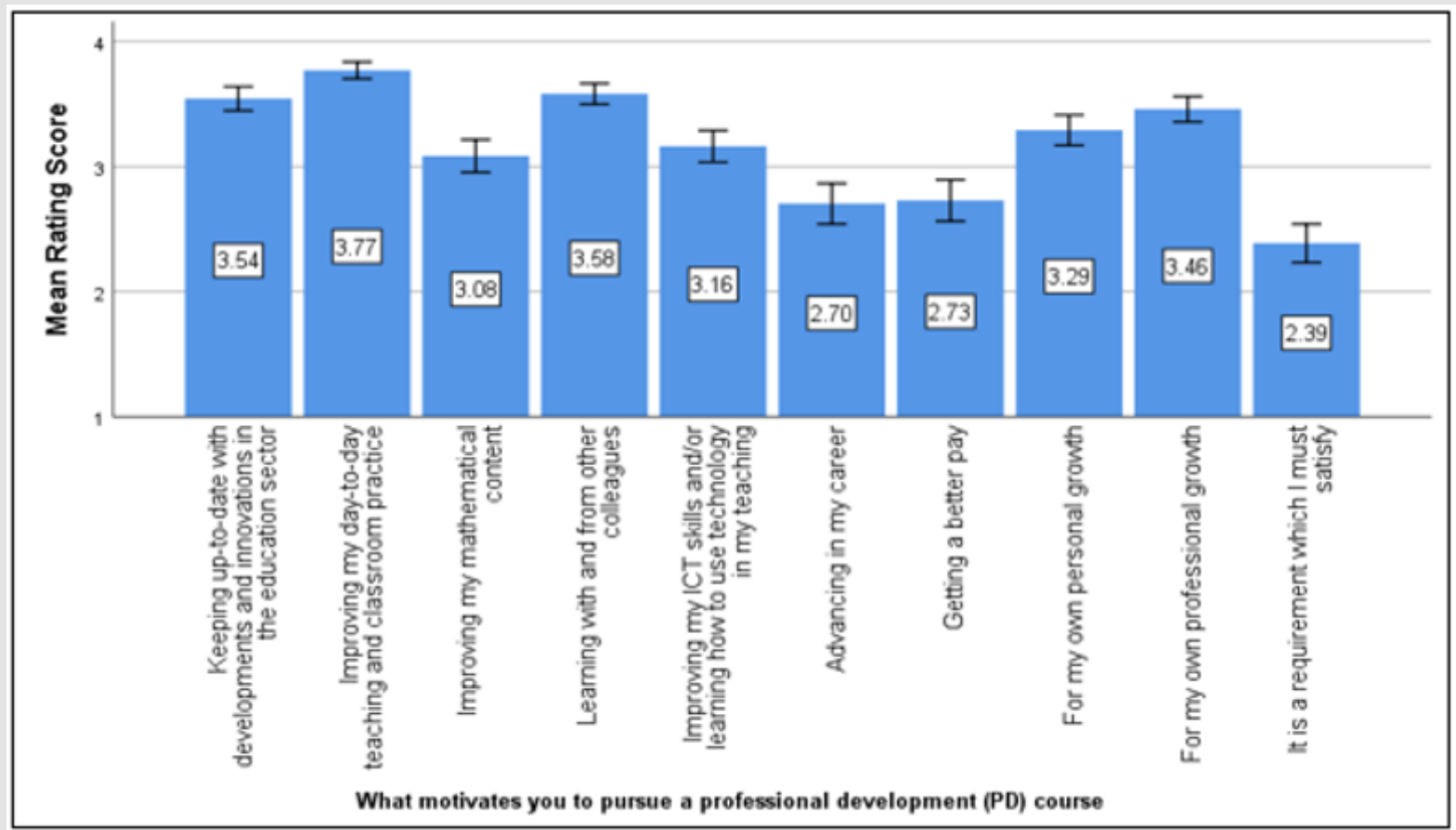

Figure 1: Bar chart displaying mean rating scores with $95 \%$ confidence intervals for statements showing motivators for teachers to pursue a PD course.

However, as stated by a focus group participant, while discussing short or long term courses, "if a teacher wishes to take on a different role, such courses are useful for one's PD as they are necessary for a career change or for career progression". Hence, it appears that there are also teachers who view PD as a means for future career advancement. In summary, participants mentioned that their PD is strongly related to a teachers' own specific intrinsic needs or to continue providing the best learning opportunities for their students. As a participant stated, "teaching comes from the soul. If you are not happy teaching, all PD sessions are in vain."

\section{Barriers to Teacher Professional Learning}

Participants identified a number of barriers that are hindering their professional learning. The barrier most frequently cited, especially with regards self-sought PD opportunities, is lack of time. Amongst reasons stated, personal responsibilities and family duties such as taking care of young children, feature frequently. Even though it is important to seek PD, time after work hours is limited. Attending courses after school hours, and seeking out my own PD opportunities are interesting options, but I have family responsibilities and have so many other things to do after work. 
I am not motivated to attend courses after school hours, as like everyone here, I have to do other things after work and I do not have time to attend a course. Albeit it is the teachers who are most aware of what is happening in their classrooms, and therefore are the most aware of their subject's specifications and requirements and also of their students' needs, at times they feel that they are not treated as professionals by School Leadership Team (SLT) or MEDE officials. Indeed, their experiences show that they have little or no say about the PD session topics offered. I need to feel that the PD would truly be of benefit to me. I often feel that some PD sessions are there simply as a filler activity and not truly effective. Teachers need to be asked on which area they would like a PD, an area of their interest. Incentives which encourage teachers to enrol in PD activities is somewhat lacking. Teachers mentioned that attending PD, especially self-sought, leads to minimal increase in pay and that there is low or practically no opportunities of career advancement. Thus, one is really not motivated to pursue PD opportunities other than those which are obligatory.

\section{Teachers' Preference and Expectations with regards Professional Development Opportunities}

Teachers participating in PD are more likely to engage in particular learning activities if they see them as relevant to their personal and professional lives. Teachers see PD opportunities as "relevant" and "effective" when these meet their expectations and needs. Teacher PD is greatly needed, and if planned well, PD activities give the teachers a boost in their job. I feel recharged after attending an effective and informative PD. Teachers think that PD should be planned in such a way as to offer them opportunities where they can work with others to produce mathematics activities, lesson plans, handouts and/or resources for their students. Discussions and the sharing of ideas are regarded as means to help ameliorate lessons, generate new and innovative ideas, and increase student learning and achievement, as this participant stated: An outsider's perspective and ideas can change your own in a positive way. It may help a teacher plan out new material and be innovative in one's lessons.

Data show that teachers value active participation during PD sessions. In addition, they believe that working on hands-on activities is relevant and stimulating. Teachers expect to be given opportunities for discussion and interaction with peers, where sharing of experiences and good practices and creation of resources is possible. Teachers in this study mentioned that, in planning for PD, time needs to be allocated for interaction - for teachers to discuss issues and to challenge critically each other's work and ideas. Such opportunities serve to stimulate their reflection on practice. Teachers also recommend incorporating workshops for lesson preparation. According to teachers, the selection of the speaker is also an important feature of an effective PD activity.
According to teachers, PD needs to bedynamicandindividualised, targeting the teachers' diverse needs and motivations. PD needs to target those specific concerns of particular individuals, so that teachers feel that their interests are taken into consideration. Moreover, they suggested to be consulted beforehand, and be given more choices and a greater say towards their PD. This section focused on the main themes emerging from the data gathered in this study. It has reviewed patterns of participation in PD activities; reasons motivating teachers to seek PD; barriers to professional learning; and the extent to which teachers perceive that certain PD activities have left an impact on them and are meeting their professional needs.

\section{Discussion and Conclusion}

This study sought to explore key issues about PD for secondary mathematics teachers in Malta and Gozo.

\section{Type of CPD Activities Mathematics Teachers Participate in}

All teachers surveyed in this study stated that they value PD and that they view PD as an integral ingredient to remain effective in their job. Teachers feel that PD provides opportunities to continuously learn new material and to update their skills and pedagogical practices. They stated that learning is a career-long commitment for them, particularly given the diverse and dynamic situations encountered in the growing and ever-changing field of education. Although labelled as important, not all teachers agree upon the amount of time they should invest in PD. Out of an average of 4.38 different PD activities attended per scholastic year by mathematics teachers, nearly all include activities held within school hours (1.90 compulsory PD activities with an additional 1.76 voluntary PD activities) with the rest, 0.72 , being self-sought PD activities. Similar findings were reported in Sammut [38] and Attard Tonna and Calleja's [17] studies, with few teachers being reported to seek self-sought PD activities other than the obligatory PD sessions held within school hours.

Analysing the participation rates for different PD opportunities for mathematics teachers, it is evident that with regards to activities held within school hours, teachers favour activities which involve dialogue with colleagues $(84.7 \%$ and $92.3 \%$ respectively for formal and informal dialogue) and collaborative preparation of teaching materials (74.3\%). Obligatory activities organised by the school and consultation meetings with teachers also hold relatively high participation rates, with similar participation rates found in research about PD of secondary school teachers conducted by Zammit [39]. With regards to participation in self-sought opportunities, teachers seem to prefer PD opportunities that can be done at home. The internet is used mainly to search for ideas to improve teaching rather than to participate in online discussions and courses (83.5\%, 26.8\% and $14.6 \%$ respectively). 


\section{PD Opportunities Teachers Perceive as Most Effective}

Data shows that teachers view PD as effective if it enhances their current personal and professional skills or facilitates learning of new skills. This finding resonates with other studies see Darling-Hammond [23,40] which show that PD courses that enhance the quality of teaching and student learning are critical for teachers. While the term 'effectiveness' is subjective, data shows that alignment of PD activities with personal and school-based objectives is important. According to Steward [41], embedding such PD principles in teacher learning is likely to offer more meaningful experiences. Data from this research suggests that mathematics teachers find PD activities effective when these go beyond a one-off meeting or session. Several teachers find that sessions organised by the school, and consultation meetings and professional learning sessions provided by MEDE have a moderate to high impact on their PD (60.6\%, 58.3\% and 58.2\% respectively). Attending seminars specifically aimed for mathematics teachers is also positively looked upon (79.6\%).

\section{What Encourages and Hinders Teachers' Participation in PD?}

Findings show that teachers are motivated to attend PD when their needs are considered, their expertise is valued, and their classroom practices and initiatives are integrated within the professional learning experience. As Attard [42] states, "just as teachers need to motivate students for learning to occur, so must teachers be motivated to learn". Over $95 \%$ of the participants rated three specific statements about their motivations for attending PD as crucial - they feel motivated to pursue a PD activity to improve their teaching and classroom practice, to keep up-to-date with developments in the education sector, and because PD provides opportunities to learn with and from their colleagues. Results from qualitative data show that mathematics teachers are motivated to attend those PD activities which helped them support students with diverse social problems and learning disabilities, which provided practical help with regards teaching in a mixed-ability setting and which helped them enhance student motivation and enthusiasm towards the subject. Teachers stated that they often felt that PD can be a means of support, with others welcoming PD targeting their well-being and providing them with ways of dealing with stressful situations. Teachers also mentioned certain barriers that hinder their participation to attend PD, with time playing a major role for PD occurring both during and after school hours. In addition, mathematics teachers see family commitments and other personal responsibilities as hindrances towards attending PD after school hours, and that they often utilise after school hours to catch up with work related to lesson planning and correction of students' work.

\section{Limitations}

The findings need to be viewed from the perspective that currently Malta is passing through new educational policies and reforms. Albeit a highly representative sample of the population was achieved, more thorough and extensive insights of the situation would have been obtained if more Independent schools had accepted the invitation to participate in the study. While this study contributes to the vast amount of international literature about the topic, still one could argue that it is about professional development for Maltese teachers, and specifically for those teaching mathematics.

\section{Implications}

Quality teaching is critical for supporting and improving student learning. Improving mathematics teaching has to do with enabling a teacher's own learning and subsequent changes in the pedagogical approaches utilised, rather than in simply introducing reforms and policies Stigler [43]. Hence, decisions taken and choices made with regards to PD provision need to ensure that these stimulate teacher learning in such a way that teaching methods, and consequently student learning, are improved. Data emerging from this study show that the majority of PD sessions occurring in schools in Malta are traditional stand-alone activities provided either nationwide by MEDE officials or organised by the schools, and mostly delivered to large groups. Studies show that single workshops are rather ineffective in changing teachers' classroom practices, even though they can be quite helpful in broadening their knowledge Ball [25]. Porter, et al. [16] suggest that to be more effective, PD sessions should be spread over a longer period of time and conducted with smaller groups of teachers. Kennedy [44] also suggests that the type of PD activities provided for teachers need to be varied, offering a means for supporting professional autonomy and transformative practice while developing different forms of knowledge. Thus, combining various PD models, both on short-term and long-term basis, may provide a more effective means of professional growth for teachers.

DuFour [45] states that collaboration at school level is highly beneficial for teachers because it increases motivation and communication amongst teachers and offers opportunities for mutual support. Postholm [46] states that teachers "want to cooperate and reflect upon practice with colleagues to change and develop their teaching". From this study, it is clear that Maltese secondary mathematics teachers prefer collaborative forms of PD. They feel that such practices offer a more effective means of development because learning is grounded both in practice and in context and is actively supported by colleagues. Collaboration positively impacts teacher morale by decreasing isolation and 
stress Punch $[45,47]$. Furthermore, teachers collectively preparing to implement changes introduced through new policies are likely to feel more confident. Thus, teacher collaboration may indirectly bring about improved teacher practice and performance through innovation, better lesson material and a higher degree of teacher decision making power Vangrieken [48].

It is also quite evident that mathematics teachers' views and say with regards PD choices and content is generally unregarded. This might have several implications. The first implication is that PD organisers and SLT rarely consult teachers with regards their PD needs, but only provide PD opportunities they deem necessary and important at that moment. With such an undertaking, a critical question arises about whose needs the PD is addressing. Hence, PD leaders need to recognise that knowledge and learning can be co-created by and with the teachers themselves Guskey [49. 51]. Working alongside teachers and involving teachers in the decision-making process is critical because it is teachers who would eventually need to bring about the 'desired' changes in their classroom. As Bubb [52] suggest, high quality PD needs to be based on teachers' needs. This is likely to imply a need for a change in the "culture" of how PD leaders do things. While this is likely to take time, a move away from top-down approaches to PD is needed. Second, it seems that only a minority of teachers seek further opportunities for PD other than those they are obliged to attend. This resonates with findings in Attard Tonna and Calleja's [17] report but contrasts with Zammit's [39] findings. Recognising that, at times, teachers face constraints to pursue self-sought PD courses, there are nowadays numerous other PD options available on the internet or through distance learning which one can participate in.

\section{Recommendations}

Teachers' PD is a very important issue and needs to be addressed strategically. Well-thought and intentionally planned PD could enhance the quality of teachers' learning Desimone, et al. [10]. The ultimate beneficiaries would be the students, who would greatly benefit from a varied and well-planned educational experience Meissel [53]. The study acknowledges that some recommendations require the involvement of persons holding senior positions, like policymakers and government entities. Activities prepared by teachers promoting good practices and innovative teaching ideas should be encouraged and supported. Also, financial support could also be provided for those teachers wishing to attend conferences or seminars both locally and abroad. This study recommends that new policies should be minimised, to allow time for teachers to gradually learn about and implement the required changes. If a new policy is needed, information and PD sessions should be provided well-ahead of the introduction of the new policy to help teachers acquire/update any required skills over a reasonable amount of time.
Sergiovanni [54] states that "one characteristic of successful schools is their ability to organise around and to effectively use collaborative cultures", where leadership and learning are brought together for continuous improvement. Unfortunately, in many schools, teaching is often an individual practice Attard Tonna [55], but evidence in all areas of life shows that many times, a collective effort can produce better results Darling-Hammond [40]. Thus, SLT should encourage and sustain a climate of collaboration in schools by promoting and supporting collaborative initiatives such as PLCs, peer observation and co-teaching. However, concurring with James [56] SLT members should be sufficiently trained to provide teachers with on-the-job support, guidance and feedback, and to positively influence teacher practice and motivation.

Even though whole school initiatives are essential, schools should focus more on subject or topic-based PD initiatives built on teachers' needs. This would make PD opportunities more meaningful for teacher growth, tailored to meet the teachers' needs and interests Bezzina [57]. [51] suggest different methodologies which are useful for mathematics teachers, such as the setting up of teacher-led Communities of Inquiry, where critical analysis of practice and of other issues central to teachers' work and lives can be discussed. Participation in Lesson Study, a PD model specifically focused on improving the teaching of mathematics through teacher group discussions, can be effective in bringing about such changes Huang [58]. This would allow teachers to make connections between research and practice, which can also be helpful for mathematics teachers Lewis [59].

\section{Concluding Reflections}

Teachers work in a fluid and complex environment, where a major source of job satisfaction is the act of teaching itself Lortie $[60,61]$. Many teachers engage in PD initiatives to improve their teaching in order to provide the best quality teaching possible for the benefit of their students Darling-Hammond [40]. Teachers need to be involved both as learners and teachers in their own development. Inquiry can be a means of raising individual and collective capacity by challenging teachers to reflect on and revise their practice, while simultaneously promoting teacher empowerment by enabling them to develop ideas outside of their usual boundaries Wall [62]. Real and sustained educational change for teachers can occur where inquiry is central to any form of PD, and where "a much more proactive and conscious approach [to change]" Kennedy [44] is utilised.

This study showed that teacher inquiry and collaborative practices can stimulate new ways of thinking and new ways of working. This study attempted to provide an overview of the current PD opportunities for mathematics teachers in Malta based on the reality perceived by the teachers themselves, a topic much 
in need of research in the local sphere. The findings indicate that while there are quite several PD opportunities available, many are provided by policy makers or planned by schools with minimal input from the teachers. Whereas all PD opportunities are essential, a critical issue must never be overlooked - that of deepening teachers' content knowledge and developing their teaching practices for them to provide quality teaching and consequently, increase student learning. A change in approach, from one where teachers are at the receiving end to one where they actively seek and/or actually lead PD, is much needed. More opportunities which focus on the teachers themselves, and which target their needs and concerns, are required. Teachers need to take more control of their own learning. This calls for a change in how teachers are involved in the decision-making process with regards PD, starting with policy makers and SLT, but most importantly the teachers themselves. A move away from top-down approaches to PD towards more teacher autonomy with regards their learning is necessary to ensure greater commitment and teacher buy-in.

\section{References}

1. (2016) Ministry for Education and Employment [MEDE]. Framework for the Education Strategy for Malta 2014-2024. Malta: Ministry of Education and Employment.

2. (2015) DQSE. Educators' Guide for Pedagogy and Assessment - Using a learning outcomes approach - Mathematics. Floriana: Directorate for Quality and Standards in Education.

3. Maskit D (2011) Teachers' attitudes toward pedagogical changes during various stages of professional development. Teaching and Teacher Education 27(5): 851-860.

4. Hunzicker J (2011) Effective Professional Development for Teachers: a checklist. Professional Development in Education 37(2): 177-179.

5. Fullan M (2007) The New Meaning of Educational Change ( $4^{\text {th }}$ Edn.)., New York: Teachers College Press.

6. (2005) OECD. Teachers Matter - Attracting, Developing and Retaining Effective Teachers. Education and Training Policy. Paris: OECD Publishing.

7. Darling-Hammond L, McLaughlin M (1995) Policies that support professional development in an era of reform. Phi Delta Kappan 76(8): 597-604.

8. Beswick K (2012) Teachers' beliefs about school mathematics and mathematicians' mathematics and their relationship to practice. Educational Studies in Mathematics 79(1): 127-147.

9. Cohen DK (1988) Teaching Practice: Plus Que Ca Change ... In: P. Jackson (Edt.)., Contributing to educational change: Perspectives on research and practice. Berkeley: McCutchan, p. 27-84.

10. Desimone LM, Porter AC, Garet MS, Yoon KS, Birman BF (2002) Effects of Professional Development on Teachers' Instruction: Results from a Three-year Longitudinal Study. Educational Evaluation and Policy Analysis 24(2): 81-112.

11. Buhagiar MA (2018) The Mathematics Teacher who became a Promoter of Inquiry-Based Learning: A Story of Teacher Change. Malta Review of Educational Research 12(1): 31-61.

12. Garet MS, Porter AC, Desimone L, Birman BF, Yoon KS (2001) What Makes Professional Development Effective? Results From a National Sample of Teachers. American Educational Research Journal 38(4): 915-945.
13. Loucks-Horsley S, Love N, Stiles KE, Mundry S, Hewson PW (2003) Designing professional development for teachers of science and mathematics (2 ${ }^{\text {nd }}$ Edn.)., Thousand Oaks, CA: Corwin Press.

14. Putnam RT, Borko H (2000) What Do New Views of Knowledge and Thinking Have to Say About Research on Teacher Learning? Educational Researcher 29(1): 4-15.

15. Quick HE, Holtzman DJ, Chaney KR (2009) Professional Development and Instructional Practice: Conceptions and Evidence of Effectiveness. Journal of Education for Students Placed at Risk 14(1): 45-71.

16. Porter AC, Garet MS, Desimone LM, Birman BF (2003) Providing Effective Professional Development: Lessons from the Eisenhower Program. Science Educator 12(1): 23-40.

17. Calleja J (2018) Teacher Participation in Continuing Professional Development: Motivating Factors and Programme Effectiveness. Malta Review of Educational Research 12(1): 5-29.

18. Krainer K (2001) Teachers' Growth is More Than the Growth of Individual Teachers: The Case of Gisela. In: F Lin, T Cooney (Eds.)., Making Sense of Mathematics Teacher Education. Dordrecht: Springer, pp. 271-293.

19. (2000) Ministry of Education. Creating the Future Together - National Minimum Curriculum. Floriana: Ministry of Education.

20. (2012) Ministry for Education and Employment [MEDE]. A National Curriculum Framework for All. Floriana: Salesian Press.

21. Fullan M (1993) Change Forces: Probing the Depths of Educational Reform. London: The Falmer Press.

22. DuFour R (2015) How PLCs do data right. Educational Leadership 73(3): 22-26.

23. DuFour R (2004) What is "professional learning community"? Educational Leadership 61(8): 6-11.

24. McLaughlin MW, Talbert JE (1993) Contexts That Matter for Teaching and Learning: Strategic Opportunities for Meeting the Nation's Educational Goals. Stanford, CA: Center for Research on the Context of Secondary School Teaching, Stanford University.

25. Ball DL (2002) What do we believe about teacher learning and how can we learn with and from our beliefs? In: D. Mewborn, P. Sztajn, D. Y. White, H. G. Wiegel, R. L. Bryant, K. Nooney (Eds.)., Proceedings of the $24^{\text {th }}$ annual meeting of the North American chapter of the international group for the psychology of mathematics education. Athens: Clearinghouse, p. 2-18.

26. Liljedahl P (2018) What teachers want from their professional learning opportunities. In: J. Haggstrom, Y. Liljekvist, J. Bergman Arleback, M. Fahlgern, O. Olande (Eds.)., Perspectives on professional development of mathematics teachers: Proceedings of MADIF11 The eleventh Swedish Mathematics Education Research Seminar. Goteborg: Swedish Society for Research in Mathematics Education, p. 9-26.

27. Creswell JW (2009) Research Design: Qualitative, Quantitative and Mixed Methods Approaches ( $3^{\text {rd }}$ Edn.)., Thousand Oaks, CA: Sage Publishers, Inc.

28. Braun V, Clarke V (2006) Using thematic analysis in psychology. Qualitative Research in Psychology 3(2): 77-101.

29. Bryman A (2012) Social Research Methods (4 $4^{\text {th }}$ Edn.)., Oxford, UK: Oxford University Press.

30. Creswell JW (2012) Educational research: planning, conducting, and evaluating quantitative and qualitative research ( $4^{\text {th }}$ Edn.)., Boston, MA: Pearson Education, Inc.

31. Creswell JW, Plano Clark VL (2018) Designing and Conducting Mixed Methods Research ( $3^{\text {rd }}$ Edn.)., Thousand Oaks, CA: Sage Publications, Inc.

32. Schutt RK (2019) Investigating the Social World: The Process and Practice ( $5^{\text {th }}$ Edn.)., Thousand Oaks, CA: Corwin. 
33. McHugh M (2013) The Chi-square test of independence. Biochemia Medica 23(2): 143-149.

34. Friedman M (1937) The Use of Ranks to Avoid the Assumption of Normality Implicit in the Analysis of Variance. Journal of the American Statictical Association 32(200): 675-701.

35. Koelsch LE (2013) Reconceptualizing the member check interview. International Journal of Qualitative Methods 12(1): 168-179.

36. Friend M, Cook L (2010) Interactions: Collaboration skills for school professionals. Upper Saddle River, NJ: Pearson.

37. Broemmel AD, Evans KR, Lester JN, Rigell A, Lockmiller CR (2019) Teacher Reading as Professional Development: Insights from a National Survey. Reading Horizons (Online) 58(1): 1-21.

38. Sammut M (2013) The Ongoing Professional Development of Teachers A Maltese Case Study. (Bachelor in Education Dissertation). Msida: University of Malta.

39. Zammit R (2020) The continuing professional development of secondary school teachers: Insights into self-sought learning. (Unpublished Master of Arts Dissertation). Msida: University of Malta.

40. Darling-Hammond L (2000) Teacher Quality and Student Achievement: A Review of State Policy Evidence. Education Policy Analysis Archives $8(1)$.

41. Steward C (2014) Transforming Professional Development to Professional Learning. Journal of Adult Education 43(1): 28-33.

42. Attard K (2007) Habitual practice vs. the struggle for change: can informal teacher learning promote ongoing change to professional practice? International Studies in Sociology of Education 17(1-2): 147162.

43. Stigler JW, Hiebert J (2009) Closing the teaching gap. Phi Delta Kappan 91(3): 32-37.

44. Kennedy A (2014) Models of Continuing Professional Development: a framework of analysis. Professional Development in Education 40(3): 336-351.

45. DuFour R (2011) Work Together: But Only if You Want to. Phi Delta Kappan Magazine 92(5): 57-61.

46. Postholm MB (2012) Teachers' professional development: a theoretical review. Educational Research 54(4): 405-429.

47. Punch K, Tuetteman E (1996) Reducing Teacher Stress: The Effects of Support in the Work Environment. Research in Education 56(1): 63-72.

\section{ISSN: 2574-1241}

DOI: $10.26717 /$ BJSTR.2022.40.006502

Robert Vella. Biomed J Sci \& Tech Res

This work is licensed under Creative

Commons Attribution 4.0 License

Submission Link: https://biomedres.us/submit-manuscript.php
48. Vangrieken K, Dochy F, Raes E, Kyndt E (2015) Teacher collaboration: A systematic review. Educational Research Review 15: 17-40.

49. Guskey TR (2003) What makes Professional Development Effective? The Phi Delta Kappan 84(10): 748-750.

50. Ronfeldt M, Farmer SO, McQueen K, Grissom JA (2015) Teacher Collaboration in Instructional Teams and Student Achievement. American Educational Research Journal 52(3): 475-514.

51. Jaworski B, Chapman 0, Clark-Wilson A, Cusi A, Esteley C, et al. (2017) Mathematics Teachers Working and Learning Through Collaboration. In: G. Kaiser (Edt.)., Proceedings of the $13^{\text {th }}$ International Congress on Mathematical Education. ICME-13 Monographs, pp. 261-276.

52. Bubb S, Earley P (2013) The use of training days: Finding time for teachers' professional development. Educational Research 55(3): 236248.

53. Meissel K, Parr JM, Timperley HS (2016) Can professional development of teachers reduce disparity in student achievement? Teaching and Teacher Education 58: 163-173.

54. Sergiovanni TJ (2006) The Principalship: A Reflective Practice Perspective. Massachusetts: Allyn \& Bacon.

55. Attard Tonna M, Shanks R (2017) The importance of environment for teacher professional learning in Malta and Scotland. European Journal of Teacher Education 40(1): 91-109.

56. James M, McCormick R (2009) Teachers learning how to learn. Teaching and Teacher Education 25(7): 973-982.

57. Bezzina C (2002) Rethinking teachers' professional development. Journal of In-service Education 28(1): 57-78.

58. Huang R, Takahashi A, da Ponte JP (2019) Theory and Practice of Lesson Study in Mathematics. Springer International Publishing.

59. Lewis C (2009) What is the nature of knowledge development in lesson study? Educational Action Research 17(1): 95-110.

60. Lortie DC (1975) School teacher: A sociological study. Chicago: University of Chicago Press.

61. Attard Tonna M, Calleja J (2018) Teachers' Professional Lives and Careers. Msida: Faculty of Education, University of Malta.

62. Wall K, Higgins S, Glasner E, Mahmout U, Gormally J (2009) Teacher Enquiry as a Tool for Professional Development: Investigating Pupils' Effective Talk While Learning. The Australian Educational Researcher 36(2): 93-117.

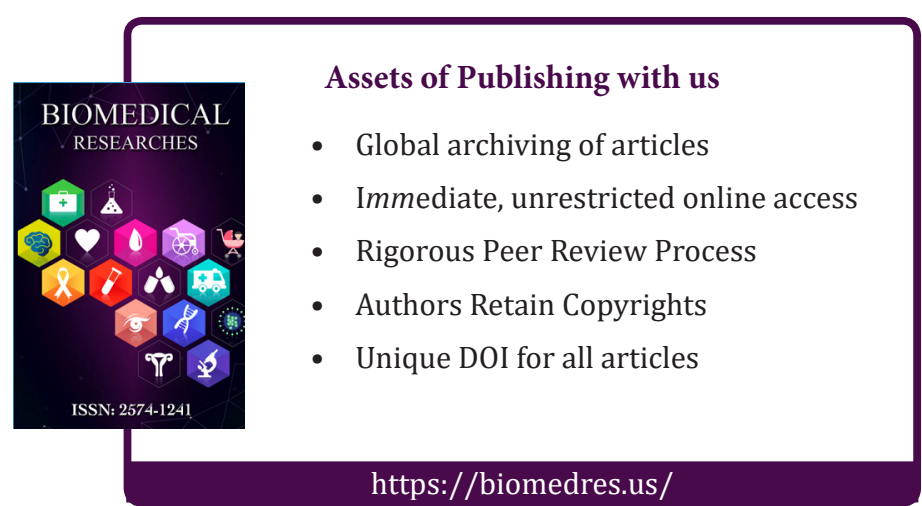

